\title{
Research on the Targeted Poverty Alleviation under the Background of Rural Revitalization in China
}

\author{
Wang XiaoFen \\ School of Public Finance and Management, \\ Yunnan University of Finance and Economics, P. R. China \\ 437535177@qq.com
}

\begin{abstract}
Targeted poverty alleviation is an important work that the Chinese government determined to realize, which is the premise and foundation for implementing the strategy of rural rejuvenation. At present, the government has to face the problems which result from targeted poverty alleviation, such as the loss of rural labor force, the disorder of local ethics and village order. It provides a new perspective of rural reconstruction to resolve the problems, such as to refactor village culture system, to foster the subject of rural microeconomic path analysis, thus condensed rural poverty consensus, resolving rural poverty conflicts of interest, strengthen villagers' sense of belonging and identity, to effectively implement targeted poverty alleviation policy.
\end{abstract}

Keywords-Rural Revitalization; Targeted Poverty Alleviation; Path Research.

\section{INTRODUCTION}

The19th congress of communist party of China puts forward to implement the strategy of rural revitalization, to complete the grand goal of build a well-off society in 2020.The necessary basis of rural revitalization is the poverty alleviation in rural areas. Targeted poverty alleviation is the major decisions made by the18th congress of communist party of China according to China's economic and social practice, which is the party and the government firmly determined to win the important "battle", then reach the "well-off society". It complement each other with the country's social structure adjustment from put forward to realize.

\section{The CurRent Situation of TARgeted Poverty}

\section{ALLEVIATION IN CHINA}

The government invest a lot of manpower and material resources, financial resources, intelligence to the rural areas since the policy of targeted poverty alleviation. The helping power and funds of poverty alleviation have precisely extended to the village to households. The basic standard of "targeted out of poverty" is to realize the farmers will not worry about food or clothing, and the rural poor will have the obligation of education, basic medical care and housing security. However, the core of targeted poverty alleviation is to ensure and improve the people's livelihood, to let farmers have more feeling of acquisition and happiness, not just in economics and demographic data for poverty reduction. In view of this, how to achieve the national poverty alleviation policy and resources in the countryside, so as to narrow the gap between the rich and the poor to achieve social equity and justice; How to follow the internal logic of good local society to realize rural good governance; How to strengthen the foundation of local culture and finally realize the all-round rejuvenation of the countryside is a subject worthy of constant exploration.

At present, China has gradually formed a longitudinal poverty alleviation mechanism from the central to local levels, the lateral poverty alleviation mechanism from the government to the social participation, and gradually formed a rural poverty governance system which consists of government-led, market promoting, social coordination and public participation. It has made great achievements in poverty alleviation work. Under the pressure of assessment indicators which from the government departments, the poverty alleviation work has achieved remarkable results. However, the rural society has also presented some obvious and potential problems, which deserve the attention of academic circles. Therefore, how to promote the structural adjustment of rural society towards a more orderly development, and an effective system of rural governance, it will help the implementation of the poverty alleviation policy, and effectively carrying out the national resources to the countryside and implementing the strategy of revitalization of the country.

\section{The LocAl Dilemma of TARGETED POVERTY ALLEVIATION WORK}

\section{A. The lost rural ethics}

According to the requirements of poverty alleviation work, the recognition and exit of people in poverty are based on dynamic management, the poverty alleviation staff and the masses should form the support relationship of "relatives", targeted obtain the situation of people in poverty and help the family out of poverty in accordance with their facts.

When villagers easily get the benefits and convenience from the government, so the villagers actively strive for government funding through contact the village cadres, their demands and approaches of poverty alleviation appeared as individual self-reliance. Get support from the government and the village cadres became the first choice of villagers to seek a path out of poverty, even someone with indolence is constantly asking for assistance from township cadres. According to the policy of precise poverty alleviation, the distribution of grants and funding in accordance with the door. In order to get more poverty alleviation resources, some villagers will not support the elderly household go out alone, ignore the traditional virtue of respect the old. With a large number of poverty alleviation funds and support force pour in 
the countryside, it not only lead to the imbalances of internal resources and labor mutual reciprocity traditional in village, and the dislocation of ethical order of the family in the presence of interests.

In the interpersonal communication of rural society, the relationship between the villagers is a balanced and stable exchange which follows the principle of reciprocity, and the mutual help of labor resources and material resources. The "reciprocity" which formed by emotion and moral obligations between villagers and traditional habits, playing the role of a core code of ethics, forming a binding obligation of the mutual recognition, therefore to achieve the balance of interpersonal exchange and interaction. Reciprocity established a social order for rural life and the whole rural society that is an important part of local order and the basic function to maintain local interpersonal. With the further development of targeted poverty alleviation work, when villagers easily get the benefits and convenience from the government, then they have lost their motivation to maintain the mutual help with their neighbors and friends. In order to get more fund or support from government, the villagers' reciprocal rights and obligations have been transformed into potential resource competition.

\section{B. The changing local order}

With the deepening concept of the rule of law, and the advancement of rural reform and national modernization, the traditional authority and local order has been influenced in the rural society. It is directly affects the rural society dispute resolution mechanism. This mechanism is not a technical question that can let the transformation of state power, but a comprehensive social work, it needs the virtuous interaction and reflective integration between rural society and the nation, and need to go beyond the legal modernization of ideology". In the case of there is more particularity in the conflict of targeted poverty alleviation.

There are three types of village disputes: the first is homestead dispute, and it is the most numerous one. The policy of targeted poverty alleviation have considerable subsidy in the renovation of rural dilapidated houses, so the enthusiasm of renovate house of the villagers was an unprecedented excitation, but the rural housing land ownership are mixed with the distribution of the self-made or problems left over by history. There exists a neighborhood or interest within the family. However, the characteristics of such disputes are the high success rate of mediation, because according to the provisions of the renovation subsidy of the dilapidated houses, there is no subsidy for the residence base of disputes, which should be distributed only after the dispute has been resolved. In order to get the state resources subsidy as soon as possible, the villagers prefer mutual tolerance and courtesy. The second category is marital family disputes. In order to increase the income and out of poverty, the villagers' migrant work has caused the couple to live apart from each other for a long time. The family relationship turn to very fragile.

The third category is the pension dispute. According to the statistics, as the rural population flow become a common phenomenon, the traditional moral obligation in the rural society is no longer be a strong and powerful binding force, and the influence of public opinion and autonomy ethical is waning in the village, and the access to resources and pursue interests gradually influences the value orientation of the villagers.

The country's resources and market economy have a deeper impact on the local order than any other force. Under the background of the modern nation-state, the rule of law has reached the local autonomy society which never reached in ancient China. It should not only respect the specification of local society, at the same time to absorb the folk wisdom and knowledge, together with the modern legal system in this work, then to achieve the target of poverty alleviation after resources passing out of poverty.

\section{The absence of main force of rural revitalization}

Rural labor flow between urban and rural areas has been the norm in the process of the present social and economic transformation, the income of migrant workers is the important way of increasing farmers' income in poverty-stricken areas, and the government take migrant labor as a key poverty alleviation work. According to X County, the migrant workers account for about 50 percent of the people who are out of poverty. For the vast majority of migrant workers, there are conflicts and contradictions between the individual values and identity of the villagers as the living space constantly changes in the cities and villages. Poor villages have become a backward area of labor loss, the problems of "hollow villages" and left-behind children and old people appeared in poverty-stricken areas. Under the background of the current social mobility between urban and rural areas in China, the development of the city is based on the support of a large number of rural labor force. To a certain extent, the "hollow village" has influenced the inner texture of the rural society. At present, China is implementing the strategy of rural revitalization, while the main executors and target objects of the strategy are not in the rural area, it means the absence of the main body of rural revitalization.

\section{The PATH OF POVERTy AlLEVIATION UNDER THE}

\section{BACKGROUND OF RURAL REVITALIZATION}

At present, under the background of big countries implement the strategy of revitalization the country, we should return to the country's local context, based on the native place to resolve the present rural plight in poverty alleviation practice. It should from the combination of traditional and modern perspective to promote targeted poverty alleviation work and to carry out the rural construction.

\section{A. To reconstruct the rural cultural system}

The traditional rural society is not only the village where the villagers were born and raised, but also the place to put their living value and identity, which is the combination of the regional and spiritual community. Therefore, to stimulate the villagers endogenous dynamic and form the consensus of out of poverty, is an important prerequisite to pass national poverty alleviation resources, and the process of village culture identification is the formation process of rural consensus. "The revival of rural culture is not only an important part of the reconstruction community, but also an important means of flexible poverty alleviation". Flexible poverty alleviation refers to the full detection and excavation of local cultural values, and to stimulate the internal development momentum of the countryside. It should highlight the cultural value and its cultural resources in the countryside, and construct rural culture system, condense consensus of out of poverty in the rural cultural consciousness, and reshape village community norms, inheritance the Chinese traditional culture, stick to the principle of reciprocity in the process of out of poverty, create a harmonious 
environment of rural governance.

\section{$B$. To reconstruct the order of rural governance}

In the rural society of China, the authority of national law is not the only principle to construct the rural order, but it is a kind of authoritative form in the authority pluralism.

The rural order of the village is deeply influenced and restricted by the political system, economic foundation and modern legal system of the country, and it is closely related to the village rules which inherited in village. At present, the rural society is facing the dual influence of the regime and capital. How to defuse the conflicts of interest or balance the forces of all parties, it is necessary to give full play to the cooperation and cooperation ability of the pluralistic subjects in rural governance in the process of the national resources of the targeted poverty alleviation.

At first, it should definite the allocation of responsibilities in targeted poverty alleviation work between multiple subject, ensure the rights and interests of different groups in the work, establish rules and regulations of rural social organization, improve the efficiency of the poverty alleviation work. At the same time, in order to avoid the poverty alleviation resources become the self-serving or power rent-seeking of some village cadres, as well as for the deviation of their interpretation of poverty alleviation policy, then result to the unfair distribution of resources and induce rural internal conflicts or hidden problems such as lower credibility of government. Therefore, it is possible to establish a public indicator system of "small and micro power" of village level to regulate the transmission process of poverty alleviation resources, and ensure the precise connection of poverty alleviation resources. It should stimulate the autonomy of rural self-government, encourage rural

$\mathrm{d}$ sharing of its resources as well as share market risks. At the same time, it needs to cultivate industry through the reform of rural collective property system for long-term benefits.

In order to motivate the development of poor areas with the method of "resource change to assets, farmers become shareholders", innovative new formats which increase the income of rural micro subjects and the villagers out of poverty. To strengthen the training of rural talent skills, to set up farmer's vocational schools or night school, to carry out practical technologies and labor skills training, to improve the ability of the villagers' income, enhance their confidence of the villagers out of poverty, gradually get rid of passive and weak state in the process of out of poverty. It is necessary to attract the rural labor back to countryside, then realize the rural governance subject of revitalization and the modernization return to its standard, gradually improve and solve the present social problems such as "hollow village".

Therefore, it should adhere to the principle of cultivating and developing rural microeconomic body in the targeted of poverty alleviation work practice, to strengthen the villagers of village belonging and identity, realize the labor backflow, the phenomenon of changing rural subject vacancy, enrich the human resources needed for the development and revitalization of countryside. It has important significance to achieve the strategy of rural revitalization.

\section{CONCLUSION}

In a word, it should follow the inherent laws of rural society development, and combine the resources of local and government from the economic and cultural level, form the multiple cooperative system of rural poor governance in the endogenous forces to participate in the enthusiasm of supervision for poverty alleviation, establish the effective mechanism of cadre's ties with the masses for long-term, implement the village-level democracy and improve the masses cohesion and satisfaction, enhance the ability of rural organization and governance.

\section{To cultivate the micro-economic subjects in the} countryside

Under the background of modern agricultural industrialization and marketization, the poverty alleviation ability and the way of increasing the income of the poor households are limited, and they are more vulnerable in dealing with the rapidly changing risks of the market. The government should be based on the actual natural resources and environment, reasonable use of resources for poverty alleviation, exploit reasonably the development of local industry, strive to guide and cultivate rural micro-economic subject, mainly embodied in the development of farmer cooperative organization, founded by developing industrial cooperatives for poverty alleviation, farmer cooperative organizations, actively explore the farmer cooperation and mutual assistance mechanism, implement effective connection of "big market and small farmers". To attract social organizations to participate in the development of peasant cooperation organizations with local characteristic resources or characteristic industries. On one hand, it is important to protect the villagers' right of cooperative project and to realize their right in the agricultural industrialization and agricultural transformation, and promote the effective integration of villagers into the rural collective development. On the other hand, the social organization needs to ensure the input an

targeted poverty alleviation work, to implement effectively the policy for poverty alleviation.

\section{REFERENCES}

[1] Chen Baifeng: Violence and Order -- the legal ethnography of Chen village in Hubei Province [J]. China Social Sciences Press, 2011, P205.

[2] Zhu Qizhen, Hu Fangmeng: flexible Poverty Alleviation: A Case Study of Poverty Alleviation by Rural Forces [J]. Journal of Agricultural University of China (social science edition), 2017(10)

[3] Xunlili: From "Resource Transfer" to "Land Management" -- Poverty Alleviation and Rural Reconstruction [J]. Cultural Aspect, 2017(11).

[4] Wan Xiuli: An Analysis of the Rural Governance in the Perspective of Targeted poverty alleviation, Gansu Social Science, 2017(2).

[5] [5]He Ping: Research on the Rule of Law in the Implementation of the Strategy of Targeted Poverty Alleviation in China [J].Law Journal, 2017(1).

[6] [6]Wang Sangui, Guo Zihao: Study on the targeted poverty alleviation in China[J]. Guizhou Social Science, 2015(5). 